BMJ Open

Diabetes

Research

$\&$ Care

\title{
Association of the Diabetes Health Plan with emergency room and inpatient hospital utilization: a Natural Experiment for Translation in Diabetes (NEXT-D) Study
}

\author{
Tannaz Moin (D) , ${ }^{1,2}$ Neil Steers, ${ }^{1}$ Susan L Ettner, ${ }^{1,3}$ Kenrik Duru, ${ }^{1}$ Norman Turk, ${ }^{1}$ \\ Charles Chan, ${ }^{4}$ Abigail M Keckhafer, ${ }^{5}$ Robert H Luchs, ${ }^{4}$ Sam Ho, ${ }^{4}$ \\ Carol M Mangione ${ }^{1,3}$
}

To cite: Moin T, Steers N, Ettner SL, et al. Association of the Diabetes Health Plan with emergency room and inpatient hospital utilization: a Natural Experiment for Translation in Diabetes (NEXT-D) Study. BMJ Open Diab Res Care 2021;9:e001802. doi:10.1136/ bmjdrc-2020-001802

Received 5 August 2020 Revised 16 November 2020 Accepted 14 December 2020
Check for updates

(C) Author(s) (or their employer(s)) 2021. Re-use permitted under CC BY-NC. No commercial re-use. See rights and permissions. Published by BMJ.

For numbered affiliations see end of article.

Correspondence to Dr Tannaz Moin;

TMoin@mednet.ucla.edu

\section{ABSTRACT}

Introduction To examine the association of a novel disease-specific health plan, known as the Diabetes Health Plan (DHP), with emergency room (ER) and hospital utilization among patients with diabetes and pre-diabetes. Research design and methods Quasi-experimental design, with employer group as the unit of analysis, comparing changes in any ER and inpatient hospital utilization over a 3-year period. Inverse probability weighting was used to control for differences between employers purchasing DHP versus standard plans. Estimated differences in utilization are calculated as average treatment effects on the treated. We used employees and dependents from employer groups contracting with a large, national private insurer between 2009 and 2012. Eligibility and claims data from continuously covered employees and dependents with diabetes and pre-diabetes $(n=74058)$ were aggregated to the employer level. The analysis included 9 DHP employers $(n=7004)$ and 183 control employers $(n=67054)$.

Results DHP purchase was associated with 2.4 and 1.8 percentage points absolute reduction in mean rates of any ER utilization, representing $13 \%$ and $10 \%$ relative reductions at 1 and 2 years post-DHP ( $p=0.012$ and $p=0.046$, respectively). There was no significant association between DHP purchase and hospital utilization. Conclusion Employers purchasing diabetes-specific health benefit designs may experience lower rates of resource-intensive services such as ER utilization.

\section{INTRODUCTION}

Employer-sponsored insurance (ESI) can help improve employee's health, maximize productivity and also reduce excessive costs. ${ }^{1-5}$ An estimated $60 \%$ of Americans obtain health insurance through ESI, ${ }^{6}$ so employer decisions regarding benefit design can impact the health of large segments of the population. In the real world, employers choose between an abundance of available benefit designs but may lack needed information to make these

\section{Significance of this study}

What is already known about this subject?

- Insurance benefit design has important implications for patients with diabetes who have high rates of healthcare utilization, including emergency room (ER) and hospital visits. The Diabetes Health Plan (DHP) is a novel health benefit designed for patients with diabetes and pre-diabetes, so we used a quasiexperimental design to examine changes in any ER and inpatient hospital utilization 1 and 2 years after DHP implementation.

What are the new findings?

- Employer group DHP purchase was associated with significant reductions in mean rates of any ER utilization at 1 and 2 years of follow-up.

- Employer group DHP purchase was not associated with any significant reductions in mean rates of any hospital utilization.

How might these results change the focus of research or clinical practice?

- Diabetes-specific health insurance benefit design may help lower ER utilization among patients with diabetes. Tailoring insurance benefit to address diabetes-specific care may enhance populationlevel approaches to the management of patients with diabetes and pre-diabetes.

important decisions. Studies have shown that employers are not always aware of clinical outcomes data, and available information often does not meet their decision-making needs. ${ }^{7}$ Thus, rigorous and real-world evaluations of insurance health benefit designs can help inform employer decisions regarding insurance benefit design.

The Diabetes Health Plan (DHP) is an example of a novel health benefit design that 
became available to public and private employer groups in 2009. The DHP is the first disease-specific health plan in the USA for patients with diabetes and pre-diabetes which offers a variety of features, such as reduced cost sharing for pharmacy and office visits and free or lowcost resources for disease management. Studies have demonstrated the benefits of disease management and lowering of copayments on the increased use of recommended services and medications among persons with diabetes. ${ }^{8-11}$ Therefore, innovative health insurance benefit designs that incorporate these evidence-based features, such as the DHP, may help optimize diabetes care across large segments of the population.

The fact that only some employer groups have purchased the DHP represents a unique opportunity to conduct a rigorous evaluation of a real-world, naturally occurring intervention, also known as a natural experiment. ${ }^{12}$ To fully examine the potential impact of the DHP, both employer and employee perspectives are key. Although these perspectives overlap in many ways, there are differences in the timing of decisions that provide a road map for our study. Typically, employers first decide whether to purchase specific health benefit plans from an insurance provider. Only after an employer chooses to purchase and offer a plan do employees have the opportunity to decide if the plan is worth engagement and to what degree. Although both perspectives are important, the first step in our evaluation of a new benefit design, such as the DHP, can focus on the employers' initial considerations regarding plan purchase.

The knowledge gained from this natural experiment is intended to help inform a population-level, or employer-level, approach to the management of patients with diabetes and pre-diabetes. Diabetes now affects more than $10 \%$ of the US population and can lead to significant morbidity. ${ }^{13}{ }^{14}$ Although diabetesrelated medical costs are on the rise,${ }^{15}$ timely and appropriate ambulatory care can help prevent many of the diabetes-related complications that often lead to costly emergency room (ER) visits and/or hospital admissions. ${ }^{16}$ An estimated $26 \%$ of all inpatient hospital days and $12 \%$ of all ER visits in the USA are incurred by patients with diabetes. ${ }^{15}$ Thus, our evaluation of the association of DHP purchase on costly ER visits and inpatient hospital admissions is a relevant and timely question for employers.

In summary, the overall goal of this study was to test whether employer group purchase of the DHP is associated with reductions in ER and inpatient hospital utilization among covered employees and dependents with diabetes and pre-diabetes. We hypothesized that an employer group purchase of the DHP benefit design would be associated with reductions in ER and inpatient hospital use among employees with diabetes and pre-diabetes as compared with employer groups who purchase standard benefit plans.

\section{METHODS}

The purchase of the DHP by some employer groups but not others represents a natural quasi-experiment in that some groups chose to purchase the DHP, and other groups chose not to purchase it, and we can observe what happens to both sets of non-randomly determined employer groups over time. These are employer-level analyses, analogous to an 'intent-to-treat' design of a theoretical trial that would have randomized purchase of the DHP at the employer level for all working-age employees and dependents (19-63 years of age) with a diagnosis of diabetes or pre-diabetes. Our employer-level analyses were conducted using administrative claims, eligibility information and laboratory data from employers who contracted with the nation's largest private insurer between 2009 and 2012. The academic team analyzed all data independently and retained sole authority over all publication-related decisions throughout the course of the study.

\section{Setting}

UnitedHealthcare (UHC) developed the DHP as a pilot program in 2009. ${ }^{17}$ The DHP has been purchased by various employer groups, including health systems, universities, school districts, and companies in a variety of industries such as technology, manufacturing, and aviation. ${ }^{17}$ DHP is marketed as a multifaceted benefit with enhancements to the standard plan in four areas: (1) eliminated copays for medications (eg, antiglycemic medications, ACE inhibitors and angiotensin receptor blockers, and statins) and reduced/eliminated copays for primary care office visits and selected specialists (eg, endocrinologists); (2) access to care management through telephonic or web-based wellness programs; (3) enhanced communication with beneficiaries via online data and adherence tracking; and (4) a compliance design that encourages adherence with evidencebased guidelines to receive enhanced benefits. ${ }^{19}$ Annual premiums are consistent across the DHP and standard benefit plans (ie, premium cost sharing is similar in both groups). Table 1 compares some of the basic health plan design features of DHP and standard plans.

\section{Study design/participants}

The study design was a non-equivalent control group quasi-experimental design in which we measured ER and inpatient hospital utilization over a continuous 3-year period-1 year prior to the purchase of the DHP and 2 years afterward (post-DHP). Among control employer groups that purchased standard plans, the preperiod was defined as the year 2010 and postperiod was defined as the years 2011 ( 1 year after) and 2012 (2 years after).

Nineteen DHP employer groups purchased the DHP between 2009 and 2010. We excluded groups that did not have available pharmacy claims (eg, contracted outside of UHC for pharmacy benefits; $n=4$ ), groups with incomplete beneficiary enrollment data or claims (eg, missing plan assignments; $n=3$ ), and groups without at least 1 year 
Table 1 Comparison of basic design features of DHP and standard medical plans purchased from UHC

\begin{tabular}{lll}
\hline Feature & DHP & Standard plan \\
\hline $\begin{array}{lll}\text { Office visit copays } \\
\quad \text { Primary care }\end{array}$ & $\$ 0$ & $\$ 20$ \\
\hline $\begin{array}{l}\text { Specialist (eg, endocrinology) } \\
\text { Prescription copays }\end{array}$ & $\$ 10$ & $\$ 30$ \\
$\quad$ Metformin, statins, ACE/ARB & $\$ 0$ & $\$ 5-\$ 15$ \\
\hline Laboratory tests & Covered & Covered \\
Online tracking & Included & Optional \\
\hline Diabetes disease management & Included & Optional \\
Weight management & Included & Optional \\
\hline
\end{tabular}

ACE, Angiotensin Converting Enzyme Inhibitor; ARB, angiotensin receptor blocker; DHP, Diabetes Health Plan; UHC, UnitedHealthcare.

of baseline data $(n=2)$ and at least 2 years of post-DHP data $(n=1)$, leaving an analytical sample of nine DHP employer groups. Of the employer groups that purchased standard plans, 1388 had available pharmacy claims (ie, contracted with UHC for pharmacy benefits) and were in similar industries and of similar size as employer groups that had purchased the DHP. In order to identify control groups most comparable to DHP groups, we conducted an employer-level propensity score match on employer size, mean income, proportion of female employees, proportion of employees with a chronic condition and generosity of benefit. ${ }^{20}{ }^{21}$ Propensity score match yielded 339 groups in the common support to serve as potential controls. $^{22}{ }^{23}$ Among these, 233 had sufficient administrative and laboratory data to identify employees with diabetes and pre-diabetes. We then excluded groups that did not have available pharmacy claims over the entire study period $(5.6 \%)$, were in the mid-Atlantic region (where no DHP employer groups were located; 9.4\%), had $>90 \%$ of employees enrolled in high-deductible health plans $(3.4 \%)$, had $<20$ employees with diabetes or pre-diabetes $(<0.01 \%)$, or had terminated their contract with UHC within the study period $(2.1 \%)$, leaving an analytical sample of 183 control employer groups.

We included data from all employees and covered dependents 19-63 years of age with a diagnosis of diabetes or pre-diabetes in the preperiod who were continuously enrolled in a UHC health plan for 3 years. Diabetes was defined by any of the following: $(1) \geq 1$ International Classification of Diseases Ninth Revision (ICD-9) diagnosis code of 250.xx from an inpatient, outpatient, or ER claim; (2) a hemoglobin A1c (HbAlc) $\geq 6.5 \%$ or a fasting plasma glucose (FPG) $>125 \mathrm{mg} / \mathrm{dL}$ or a 2-hour oral glucose tolerance test (OGTT) value of $>200 \mathrm{mg} / \mathrm{dL}$; (3) $\geq 1$ prescription fill for insulin or an antiglycemic medication other than metformin. Pre-diabetes was defined by any of the following: (1) $\geq 2$ ICD-9 diagnoses of $790.2 x$ from an inpatient, outpatient, or ER claim; (2) last HbAlc value of $5.7 \%-6.4 \%$ or last fasting blood glucose value of $100-125 \mathrm{mg} / \mathrm{dL}$ or last 2-hour OGTT value of $140-199 \mathrm{mg} / \mathrm{dL}$. We excluded patients with a history of pregnancy within 1 year of diagnosis (ie, gestational diabetes). For employer groups that purchased the DHP, data from all eligible employees and covered dependents with diabetes and pre-diabetes were included, regardless of enrollment in DHP (eg, if the employee chose to opt out of DHP and enroll in a standard plan). This was consistent with an intent-to-treat design to help inform a population-level, or employer-level, approach to the management of patients with diabetes and pre-diabetes.

\section{Measurement/variables}

At the individual level, ER and hospital utilization were measured as binary 'any use' versus 'no use' variables in each of the three study periods (baseline, 1 year and 2 years after) for each employee and their dependents between 19 and 63 years of age with pre-diabetes and diabetes. The individual-level measures were then aggregated up to construct employer group mean values. The primary outcomes of interest were these employer-level mean rates of ER and hospital utilization. Annual utilization for each follow-up period (1 year and 2 years after) was calculated independently of other years.

\section{Statistical analyses}

Inverse probability weighting (IPW) was used to control for differences between employer groups who purchased the DHP and those who purchased standard plans on several variables hypothesized to be predictive of ER and inpatient hospital utilization. IPW allows for control of confounders when randomization is not possible and can be used to emulate hypothetical randomized trials of interest using observational data. ${ }^{24}$ This method involves calculating the conditional probability, or propensity, of being in the treatment group (in this case the probability that an employer group purchased the DHP) given a set of covariates. ${ }^{24}$

We included two categories of employer-level variables in the propensity model. The first category of variables included in this study was employer-level means and proportions from all employees and covered dependents routinely collected by UHC including: (1) mean level of education; (2) mean income; (3) the proportion of employees with one or more chronic medical conditions; (4) proportion of employees with diabetes or pre-diabetes at baseline; (5) proportion of employees enrolled in high-deductible health plans; (6) a proprietary estimate of future medical cost risk from the perspective of UHC; (7) the proportion of employees within different demographic groups as identified by UHC (\% White, $\%$ Hispanic, \% African American, \% Asian, \% Other race); and (8) location of the employer group by geographic region. The second category of variables was constructed for the purpose of this study using employer-level means and proportions from employees and covered dependents between 19 and 63 years of age with diabetes and pre-diabetes and included: (1) mean age; (2) proportion 
of female employees; and (3) proportion of employees with any ER or inpatient hospital utilization in the preperiod (ie, baseline measure of utilization).

The resulting inverse probability weights (IPWs) were then used to estimate the average treatment effects on the treated (ATET) for ER and hospital utilization measures without DHP exposure. The ATET reflects the adjusted difference among DHP employers in the mean rates of any utilization (ER or inpatient hospital) associated with purchase of the DHP compared with mean rates of utilization if those employers had not purchased the DHP, as derived via model adjustment incorporating control employer data. All analyses were conducted using STATA V.13, with IPW and ATET simultaneously estimated using the 'TEFFECTS' command.

\section{RESULTS}

Our analytical sample included nine employer groups that purchased the DHP and 183 control employer groups that purchased standard plans. Data from 74058 eligible employees and covered dependents with diabetes and pre-diabetes, of which $9.3 \%(\mathrm{n}=7004)$ belonged to employer groups that purchased the DHP and 90.7\% $(n=67054)$ belonged to control groups that purchased standard plans, were aggregated to the employer level. IPWs were used to weight treatment and control groups so they were balanced on all baseline measures. Tests of inverse probability-weighted disparity between DHP and control employer groups showed no significant differences between groups on any variables measured at baseline, including the baseline measures of utilization, indicating that the groups were balanced. Data from 74058 eligible employees and covered dependents with diabetes and pre-diabetes, of which 9.3\% ( $\mathrm{n}=7004)$ belonged to employer groups that purchased the DHP and $90.7 \% \quad(n=67054)$ belonged to control groups that purchased standard plans, were aggregated to the employer level (table 2).

There was no evidence of any differences in weighted mean rates of ER and hospital utilization at 1 and 2 years after. However, tests of ATET estimates indicated a significant difference in mean rates of any ER utilization at 1 and 2 years after DHP purchase. Employer groups that purchased the DHP were predicted to have a mean rate of any ER utilization that was 2.4 percentage points lower than would have been predicted in the absence of DHP purchase at year $1(18.9 \%$ vs $16.5 \%, \mathrm{p}=0.012$, table 3$)$.

Table 2 Baseline characteristics of DHP and control employer groups

\begin{tabular}{|c|c|c|c|}
\hline Employer-level characteristic & DHP employers $(n=9)$ & Control employers $(n=183)$ & $P$ value \\
\hline \multicolumn{4}{|l|}{ Employer demographics } \\
\hline Mean employee age (SD) & $50.7(3.4)$ & $50.2(0.6)$ & 0.658 \\
\hline Proportion female (SD) & $41.7(8.7)$ & $42.3(1.8)$ & 0.828 \\
\hline Mean employee salary (SD) & $\$ 64503$ (5902) & $\$ 64511(5390)$ & 0.997 \\
\hline Mean number of employees (SD) & $10321(9970)$ & $10628(5390)$ & 0.937 \\
\hline Proportion of employees with diabetes or pre-diabetes (SD) & $3.3(1.6)$ & $3.3(0.3)$ & 0.913 \\
\hline \multicolumn{4}{|l|}{ Race/ethnicity distribution } \\
\hline Mean \% White (SD) & $61.0(13.8)$ & $59.9(2.7)$ & 0.808 \\
\hline Mean \% Black American (SD) & $9.2(12.3)$ & $9.6(1.8)$ & 0.923 \\
\hline Mean \% Asian (SD) & $2.2(1.3)$ & $2.2(0.5)$ & 0.905 \\
\hline Mean \% Latin/Hispanic (SD) & $17.7(13.6)$ & $18.4(2.9)$ & 0.884 \\
\hline Mean \% Other race (SD) & $3.4(2.7)$ & $2.5(0.3)$ & 0.339 \\
\hline \multicolumn{4}{|l|}{ Region (\%) } \\
\hline West & 44 & 48 & \\
\hline Southeast & 33 & 36 & \\
\hline Central Atlantic & 11 & 4 & \\
\hline New England & 11 & 12 & \\
\hline Proportion with high-deductible plan (SD) & $3.1(5.0)$ & $3.4(2.6)$ & 0.873 \\
\hline Proportion with comorbidities (SD) & $35.4(4.2)$ & $35.1(1.3)$ & 0.846 \\
\hline \multicolumn{4}{|l|}{ Baseline utilization, by employer } \\
\hline Proportion with any ER utilization in the preperiod (SD) & $18.2(3.8)$ & $18.3(0.9)$ & 0.985 \\
\hline $\begin{array}{l}\text { Proportion with any inpatient hospital utilization in the } \\
\text { preperiod (SD) }\end{array}$ & $10.9(3.3)$ & $10.6(0.5)$ & 0.817 \\
\hline
\end{tabular}

DHP, Diabetes Health Plan; ER, emergency room. 
Table 3 ER and inpatient hospital utilization at the employer level: absolute and relative difference in predicted utilization without DHP exposure versus actual utilization with DHP exposure

\begin{tabular}{|c|c|c|c|c|c|}
\hline & $\begin{array}{l}\text { Predicted } \\
\text { utilization without } \\
\text { DHP exposure* }\end{array}$ & $\begin{array}{l}\text { Actual utilization } \\
\text { with DHP } \\
\text { exposure }\end{array}$ & $\begin{array}{l}\text { Absolute } \\
\text { difference }\end{array}$ & $\begin{array}{l}\text { Relative } \\
\text { difference }\end{array}$ & P value \\
\hline ER utilization at 1 year post-DHP & $18.9 \%$ & $16.5 \%$ & -2.4 percentage points & $\begin{array}{l}13 \% \\
\text { reduction }\end{array}$ & 0.012 \\
\hline ER utilization at 2 years post-DHP & $18.9 \%$ & $17.1 \%$ & -1.8 percentage points & $\begin{array}{l}10 \% \\
\text { reduction }\end{array}$ & 0.046 \\
\hline $\begin{array}{l}\text { Inpatient hospital utilization at } 1 \text { year } \\
\text { post-DHP }\end{array}$ & $10.3 \%$ & $10.0 \%$ & -0.3 percentage points & $\begin{array}{l}3 \% \\
\text { reduction }\end{array}$ & 0.737 \\
\hline $\begin{array}{l}\text { Inpatient hospital utilization at } 2 \\
\text { years post-DHP }\end{array}$ & $10.9 \%$ & $10.7 \%$ & -0.2 percentage points & $\begin{array}{l}2 \% \\
\text { reduction }\end{array}$ & 0.803 \\
\hline
\end{tabular}

${ }^{*}$ Adjusted for the following employer-level variables in a propensity model: mean employee age, \% female, race/ethnicity (\% White, \% Hispanic, \% African American, \% Asian, \% Other race), \% with diabetes or pre-diabetes, mean income, UnitedHealthcare (UHC) estimated medical cost risk score, geographic region, number of employees, \% of employees with a high-deductible health plan, overall generosity of benefit, \% with chronic comorbidities, baseline utilization measure. DHP, Diabetes Health Plan; ER, emergency room.

This 2.4 percentage point absolute reduction represented a $13 \%$ relative reduction in adjusted mean rates of any ER utilization associated with an employer group purchase of the DHP compared with predicted rates had they not purchased the DHP. At year 2, there was a 1.8 percentage point absolute reduction representing a $10 \%$ relative reduction in adjusted mean rates of any ER utilization ( $18.9 \%$ vs $17.1 \%, \mathrm{p}=0.046$, table 3$)$. However, we found no evidence of any significant reduction in predicted inpatient hospital utilization at 1 and 2 years post-DHP associated with DHP purchase.

\section{DISCUSSION}

Our results show that the purchase of DHP was associated with a $13 \%$ relative reduction in the mean rates of ER utilization by 1 year after DHP purchase and $10 \%$ relative reduction by 2 years post-DHP compared with the expected ER use without the purchase of the DHP. We did not find any significant association between an employer group purchase of the DHP and adjusted rates of inpatient hospital utilization among the same population. These findings suggest that benefit designs that decrease out-of-pocket costs for office visits, medications, and disease support programs may play an important role in decreasing the cost for more resource-intensive services such as ER utilization for persons with diabetes and pre-diabetes.

Our findings are likely to be of interest to key stakeholders, including employers who make decisions about whether to invest in purchasing health plans with innovative benefit designs in the real world, but also policymakers, public insurance programs and patients themselves. Our findings suggest that if widespread access to a disease-specific health plan, such as the DHP, was available for patients with diabetes and pre-diabetes, ER utilization may be significantly reduced over a relatively short time frame.
Diabetes-related care already accounts for approximately 1 in every 5 healthcare dollars in the USA. ${ }^{15}$ Studies have demonstrated that patients with diabetes are more likely to use emergency medical services, to be admitted to the hospital after an ER visit, to have longer lengths of hospital stay, and to experience multiple hospitalizations in a given year. ${ }^{26-29}$ Each of these utilization measures represents a potential opportunity to improve quality and reduce costs of diabetes care. The findings from this natural experiment allude to the potential for significant impact in these current gaps.

The mechanism by which an employer's DHP purchase may lead to reductions in ER utilization is not yet clear. We previously found increased diabetes-related medication adherence among employees and covered dependents with diabetes in employer groups purchasing the DHP as compared with standard benefit plans. ${ }^{30}$ Since increased medication adherence has been shown to be associated with lower rates of complications and fewer ER visits among patients with diabetes, this would be one possible explanation. ${ }^{31}$ Deciphering if one DHP design feature is primarily associated with lowering ER utilization was outside the scope of this study, but will be the focus of future work.

Though our hypothesis regarding inpatient hospital utilization was not supported, we are not surprised to find a lack of association between DHP purchase and inpatient hospital use. The leading causes of hospitalization of patients with diabetes are chronic conditions, such as congestive heart failure and coronary atherosclerosis, that take years to develop. ${ }^{28}$ Exceptions may be pneumonia and septicemia, but a 3-year study interval with a 2-year post implementation interval is probably not long enough to anticipate any impact on hospital utilization, if one does in fact exist. Long-term studies are needed to assess DHP impact on hospital utilization, as well as long-term health outcomes for patients with diabetes and 
pre-diabetes. These are critical and unanswered questions we will focus on as additional years of follow-up become available.

This intent-to-treat, employer-level design provides insight on the potential impact of the DHP at a population level, keeping limitations of the real-world setting in mind. Natural quasi-experiments like ours provide a unique opportunity to generate knowledge where it did not previously exist but there are limitations, such as unmeasured selection effects and possible cointerventions at the employer level. Our employer groups were balanced on all measures at baseline, and our study design effectively compares changes in outcomes over time (as opposed to comparing outcomes at a single point in time). However, there may still be unmeasured differences that impact the time trajectories of our outcomes of interest and therefore bias the quasi-experimental comparison. Additionally, our study focused on any ER or inpatient utilization, as opposed to diabetes-related use. Claims data usually do not include important process measures of diabetes care, such as glucose or blood pressure control, which remain outside the scope of our analysis. Lastly, our analysis was focused on stably commercially insured adults 19-63 years of age, which limits the generalizability of findings to working-age patients with diabetes and pre-diabetes. However, this segment of the population is responsible for a significant portion of pre-diabetes and diabetes cases. Of the 1.9 million new diagnoses of diabetes in the USA in 2010 , almost $80 \%$, or 1.5 million, occurred in adults between the ages of 20 and 64 years. ${ }^{32}$ Adults aged $18-64$ years also account for $56 \%$ of all diabetes-related ER visits. ${ }^{27}$ Thus, our findings, although limited to stably commercially insured adults between the ages of 18 and 63, are applicable to a large subpopulation of people with diabetes or pre-diabetes.

In conclusion, purchase of the DHP was associated with a $13 \%$ relative reduction in adjusted mean rates of ER utilization at year 1 and $10 \%$ at year 2 but no change in hospital use among working-age adults with diabetes and pre-diabetes. Our findings indicate that health insurance benefit designs that lower out-of-pocket costs for office visits, medications and chronic disease management programs may play an important role in decreasing the cost for more resource-intensive services such as ER utilization for persons with diabetes and pre-diabetes.

\section{Author affiliations}

${ }^{1}$ David Geffen School of Medicine, University of California Los Angeles, Los Angeles, California, USA

${ }^{2}$ Center for the Study of Healthcare Innovation, Implementation and Policy, VA Greater Los Angeles Healthcare System, Los Angeles, California, USA

${ }^{3}$ Jonathan and Karin Fielding School of Public Health, University of California Los Angeles, Los Angeles, California, USA

${ }^{4}$ United Healthcare Services, Minneapolis, Minnesota, USA

${ }^{5}$ United Health Group, Minnetonka, Minnesota, USA

Acknowledgements The authors would like to thank Ms Karen Mulready and Ms Anya Kirvan for their assistance in acquiring the UHC data necessary to conduct this study. The authors would also like to thank Ms Lindsay Kimbro Brooker and Ms Carolina Vasquez for their administrative and project management support. Lastly, the authors would like to thank the entire NEXT-D research network for invaluable support and guidance throughout this study.

Contributors All authors (1) made substantial contributions to conception and design, acquisition of data, or analysis and interpretation of data, (2) drafted the article or revised it critically for important intellectual content, (3) gave final approval of the version to be published, and (4) agreed to be accountable for all aspects of the work in ensuring that questions related to the accuracy or integrity of any part of the work are appropriately investigated and resolved. Study concept and design: CMM, KD, SLE. Acquisition of data: CC, RHL, AMK, SH. Analysis and interpretation of data: CMM, KD, SLE, TM, NS, NT. Drafting of the manuscript: TM. Critical revision of the manuscript for important intellectual content: CMM, KD, SLE, NS, NT, TM. Statistical analysis: SLE, NS, NT. Obtained funding: CMM, KD. Administrative, technical, or material support: all authors. Study supervision: CMM, $\mathrm{KD}$.

Funding This study was jointly funded by the Centers for Disease Control and Prevention (Division of Diabetes Translation) and the National Institute of Diabetes and Digestive and Kidney Diseases as part of the Natural Experiments for Translation in Diabetes (NEXT-D) Study (grant number DP002722).

Disclaimer This article does not necessarily represent the views and policies of the USPSTF

Competing interests TM received support from the Department of Veterans Affairs under grants QUE15-272, QUE15-286, and CSP2002, the NIH/National Istitute of Diabetes and Digestive and Kidnet Disease (NIDDK) under grant 1R01DK124503-01 and the Centers for Disease Control and Prevention (CDC) under grant U18DP006140.CMM and KD received support from the University of California at Los Angeles (UCLA), by the NIH/NIDDK under grant R18DK105464, the CDC under grant U18DP006140, and from the Patient-Centered Outcomes Research Institute (PCORI) under grant SDM-2018C2-13543. CMM also received support from NIH/National Center for Advancing Translational Sciences UCLA Clinical and Translational Science Institute under grant UL1TR001881. CMM holds the Barbara A Levey and Gerald S Levey Endowed Chair in Medicine, which partially supported her work. CMM is a member of the United States Preventive Services Task Force (USPSTF). KD also received support from the Terasaki Family Foundation under grant 20191425. CMM, KD and NS received support from the Resource Centers for Minority Aging Research Center for Health Improvement of Minority Elderly under National Institutes of Health (NIH)/NIA under grant P30AG021684.

Patient consent for publication Not required.

Ethics approval This study has obtained ethics approval from the UCLA Institutional Review Board (IRB number 16-000276-CR-00005). No human subjects were used in this study.

Provenance and peer review Not commissioned; externally peer reviewed.

Data availability statement Data requests can be submitted to UnitedHealthcare. The data that support the findings of this study are not publicly available and proprietary to UnitedHealthcare.

Open access This is an open access article distributed in accordance with the Creative Commons Attribution Non Commercial (CC BY-NC 4.0) license, which permits others to distribute, remix, adapt, build upon this work non-commercially, and license their derivative works on different terms, provided the original work is properly cited, appropriate credit is given, any changes made indicated, and the use is non-commercial. See: http://creativecommons.org/licenses/by-nc/4.0/.

ORCID iD

Tannaz Moin http://orcid.org/0000-0002-5035-6641

\section{REFERENCES}

1 Eisenberg JM, Power EJ. Transforming insurance coverage into quality health care: voltage drops from potential to delivered quality. JAMA 2000;284:2100-7.

2 Fowler RA, Noyahr L-A, Thornton JD, et al. An official American thoracic Society systematic review: the association between health insurance status and access, care delivery, and outcomes for patients who are critically ill. Am J Respir Crit Care Med 2010;181:1003-11.

3 Baker DW, Sudano JJ, Albert JM, et al. Lack of health insurance and decline in overall health in late middle age. N Engl $\mathrm{J} \mathrm{Med}$ 2001;345:1106-12.

4 Hadley J. Sicker and poorer--the consequences of being uninsured: a review of the research on the relationship between health 
insurance, medical care use, health, work, and income. Med Care Res Rev 2003;60:3S-75.

5 Vistnes JP, Cooper PF, Vistnes GS. Employer contribution methods and health insurance premiums: does managed competition work? Int J Health Care Finance Econ 2001;1:159-87.

6 Sonier J, Fried B, Au-Yeng C. State-level trends in employersponsored health insurance Minneapolis. MN: University of Minnesota, 2013.

7 Hibbard JH, Jewett JJ, Legnini MW, et al. Choosing a health plan: do large employers use the data? Health Aff 1997;16:172-80.

8 Duru OK, Mangione CM, Chan C, et al. Evaluation of the diabetes health plan to improve diabetes care and prevention. Prev Chronic Dis 2013;10:E16.

9 Mangione CM, Gerzoff RB, Williamson DF, et al. The association between quality of care and the intensity of diabetes disease management programs. Ann Intern Med 2006;145:107-16.

10 Karter AJ, Stevens MR, Herman WH, et al. Out-Of-Pocket costs and diabetes preventive services: the translating research into action for diabetes (triad) study. Diabetes Care 2003;26:2294-9.

11 Tseng C-W, Tierney EF, Gerzoff RB, et al. Race/ethnicity and economic differences in cost-related medication underuse among insured adults with diabetes: the translating research into action for diabetes study. Diabetes Care 2008:31:261-6.

12 Gregg EW, Ali MK, Moore BA, et al. The importance of natural experiments in diabetes prevention and control and the need for better health policy research. Prev Chronic Dis 2013;10:E14.

13 CDC. National diabetes fact sheet: national estimates and general information on diabetes and prediabetes in the United States. Atlanta, GA: U.S. Department of Health and Human Services, Centers for Disease Control and Prevention, 2011.

14 Boyle JP, Thompson TJ, Gregg EW, et al. Projection of the year 2050 burden of diabetes in the US adult population: dynamic modeling of incidence, mortality, and prediabetes prevalence. Popul Health Metr 2010;8:29.

15 American Diabetes Association. Economic costs of diabetes in the U.S. in 2012. Diabetes Care 2013;36:1033-46.

$16 \mathrm{AHRQ}$. AHRQ quality Indicators - Guide to prevention quality indicators: hospital admission for ambulatory care sensitive conditions. Rockville, MD: Agency for Healthcare Research and Quality, 2004.

17 UnitedHealth Group - Diabetes Health Plan. Available: https://www. unitedhealthcareonline.com/b2c/CmaAction.do?channelld=e668 5b4365272210VgnVCM2000003010b10a [Accessed 2 Jan 2014].

18 Heilbrunn E. Top health insurance companies, 2013. Available: http://health.usnews.com/health-news/health-insurance/articles/ 2013/12/16/top-health-insurance-companies [Accessed 28 Dec 2013]

19 Weintraub A, Love T. Lower Health Costs. Bloomberg Business Week Magazine, 2009. Available: http://www.businessweek.com/ stories/2009-10-21/tough-love-lower-health-costs [Accessed 21 Oct 2009].

20 McDonald RJ, McDonald JS, Kallmes DF, et al. Behind the numbers: propensity score analysis-a primer for the diagnostic radiologist. Radiology 2013;269:640-5.

21 Heinze G, Jüni P. An overview of the objectives of and the approaches to propensity score analyses. Eur Heart $J$ 2011;32:1704-8.

22 Dehejia RH, Wahba S. Causal effects in Nonexperimental studies: Reevaluating the evaluation of training programs. J Am Stat Assoc 1999;94:1053-62.

23 Stuart EA. Matching methods for causal inference: a review and a look forward. Stat Sci 2010;25:1-21.

24 Curtis LH, Hammill BG, Eisenstein EL, et al. Using inverse probability-weighted estimators in comparative effectiveness analyses with observational databases. Med Care 2007; 45:S103-7.

25 Rosenbaum PR, Rubin DB. The central role of the propensity score in observational studies for causal effects. Biometrika 1983;70:41-55

26 Knowlton A, Weir BW, Hughes BS, et al. Patient demographic and health factors associated with frequent use of emergency medical services in a midsized City. Acad Emerg Med 2013;20:1101-11.

27 Washington R, Andrews R, Mutter R. Emergency department visits for adults with diabetes, 2010. healthcare cot and utilization project: agency for healthcare reform and quality (AHRQ), 2013.

28 Fraze T, Jiang J, Burgess J. Hospital stays for patients with diabetes, 2008. healthcare cost and utilization project: agency for healthcare research adn quality (AHRQ), 2010

29 Jiang HJ, Stryer D, Friedman B, et al. Multiple hospitalizations for patients with diabetes. Diabetes Care 2003;26:1421-6.

30 Duru OK, Turk N, Ettner SL, et al. Adherence to metformin, statins, and ACE/ARBs within the diabetes health plan (DHP). J Gen Intern Med 2015;30:1645-50

31 Gibson TB, Song X, Alemayehu B, et al. Cost sharing, adherence, and health outcomes in patients with diabetes. Am J Manag Care 2010;16:589-600.

32 Clearinghouse NDI. National diabetes statistics, 2011. National diabetes information Clearinghouse National Institute of diabetes and digestive and kidney disorders, National Institue of health, 2011. 